\title{
Application of FTIR spectroscopy and multivariate calibration for determination of Acid Orange 7 and Sudan II in blusher products
}

\author{
Novalina B. R. Purba ${ }^{1,2}$, Abdul Rohman ${ }^{1 *}$, Sudibyo Martono ${ }^{3}$ \\ ${ }^{1}$ Department of Pharmaceutical Chemistry, Faculty of Pharmacy, Universitas Gadjah Mada, Yogyakarta 55281, Indonesia. \\ ${ }^{2}$ The National Agency of Drug and Food Control, District of Denpasar 80235, Bali, Republic of Indonesia. \\ ${ }^{3}$ Institute of Halal Industry and System (IHIS), Universitas Gadjah Mada, Yogyakarta 55281, Indonesia.
}

\begin{tabular}{|c|c|}
\hline ARTICLE INFO & ABSTRACT \\
\hline $\begin{array}{l}\text { Received on: } 24 / 05 / 2019 \\
\text { Accepted on: } 26 / 08 / 2019 \\
\text { Available online: } 04 / 11 / 2019\end{array}$ & $\begin{array}{l}\text { The aim of this study was to optimize Fourier transform infrared (FTIR) spectroscopy and multivariate calibration } \\
\text { for the quantitative analysis of Acid orange } 7 \text { (AO-7) and Sudan II (S-II) in blusher products. The calibration and } \\
\text { validation samples were made by adding known concentrations of AO-7 and S-II in the placebo of blusher cosmetics } \\
\text { products. High-performance liquid chromatography equipped with photodiode array detector at } 300-650 \mathrm{~nm} \text { was }\end{array}$ \\
\hline $\begin{array}{l}\text { Key words: } \\
\text { Acid orange 7, Sudan II, } \\
\text { HPLC, FTIR multivariate, } \\
\text { PLSR, PCR, Blusher. }\end{array}$ & $\begin{array}{l}\text { used to determine the actual values of AO- } 7 \text { and S-II. The separation of AO- } 7 \text { and S-II was performed using C18 } \\
\text { column at } 40^{\circ} \mathrm{C} \text { with mobile phase of acetonitrile-water in gradient elution program. FTIR spectra of evaluated } \\
\text { samples were scanned using FTIR spectrophotometer equipped with attenuated total reflectance (ATR) sampling } \\
\text { technique. The correlation between actual values of AO-7 and S-II as determined using high-performance liquid } \\
\text { chromatography and FTIR predicted values was facilitated with multivariate calibrations. The selection of calibration } \\
\text { models relied on highest } r^{2} \text { and lowest levels of root mean square error of calibration, root mean square error of } \\
\text { prediction, and root mean square error of cross validation. The optimization results showed that FTIR spectra-partial } \\
\text { least square regression (PLSR) using wavenumbers of 3,450-2,400 } \mathrm{cm}^{-1} \text { and six factors offered the highest } r^{2} \text { value } \\
\left(r^{2}>0.98\right) \text { and lowest errors. FTIR with ATR technique could be used to predict AO-7 and S-II in blusher product with } \\
\text { the main advantage of its simplicity, rapidity, and minimum sample preparation. }\end{array}$ \\
\hline
\end{tabular}

\section{INTRODUCTION}

Dyes are taken into account as "key property" of cosmetics product intended to attract the consumer's preference and, as a consequence, dyes are very effective means for the successful marketing, especially in the era of social media. In cosmetics industry, dyes are among cosmetics components with strong growth due to the increased concern of human body color, especially women (Fardouly et al., 2016). There are two types of dye agents, namely, natural and synthetic. The cosmetics industry prefers to use synthetic dyes due to its low cost, stable toward

${ }^{*}$ Corresponding Author

Abdul Rohman, Department of Pharmaceutical Chemistry, Faculty of Pharmacy, Universitas Gadjah Mada, Yogyakarta 55281, Indonesia. E-mail:abdul_kimfar@ugm.ac.id heat and extreme $\mathrm{pH}$ which occurred during production, and longacting property in terms of brightness (Guerra et al., 2018).

Acid Orange 7 (AO-7) is a synthetic dye that is permitted in cosmetic preparations. Based on the regulation of the Head of National Agency of Drug and Food Control Number 18, 2015 concerning technical requirements for cosmetic materials, AO-7 is permitted to use except around the eyes. Because of its color similarity, AO7 is often replaced with Azo Solvent Orange 7 or better known as Sudan II. The chemical structures of AO-7 and S-II were depicted in Figure 1. S-II is known to be harmful to humans because it is toxic to the liver, mutagenic, and carcinogenesis (Pan et al., 2011). Many studies on the toxicity of dyes have been reported so that regulations should be applied to limit the levels of AO-7 and S-II in cosmetics preparations (An et al., 2007; Ben Mansour et al., 2007). When this regulation is applied, a valid method is needed for determining the contents of AO-7 and S-II in some products including food, cosmetics, and pharmaceutical products. 


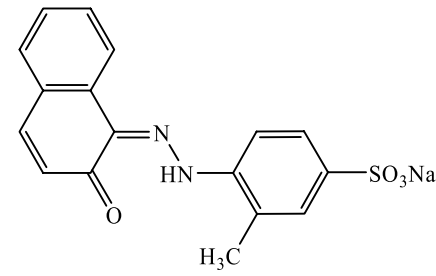

Acid orange 7

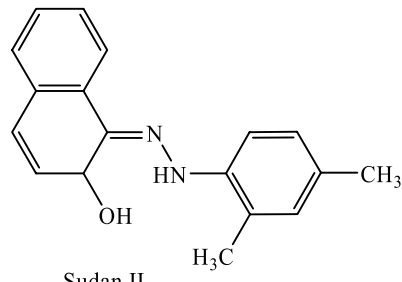

Sudan II
Figure 1. The chemical structures of Acid orange 7 and Sudan II.

The reported methods for quantitative analysis of dyes focused on food samples (Kucharska and Grabka, 2010). In cosmetics preparations, the methods used for determination of cosmetics ingredients were regulated into the European Regulation 1223/2009 (Buzek et al., 2009; Rebane et al., 2010; Yamjala et al., 2016). Most of the reported methods for analysis of AO-7 and S-II were performed by simultaneous determination with other dyes which include enzyme-linked immunosorbent assay or ELISA (Ju et al., 2008), high-performance liquid chromatography using photodiode array (PDA) detector (Ertas et al., 2007; Purba et al., 2019), and mass spectrometer detector (Souto and Catia Susana, 2010). High-performance liquid chromatography (HPLC) is a method of choice for determination of dyes due to its sensitivity and its capability to provide the separation of targeted analytes (Prabaningdyah et al., 2018). However, this method is time consuming (requires 13 minutes for complete separation of the two dyes) and need excessive solvents (mobile phase); therefore, a simple and fast reliable analytical method is developed to overcome this obstacle. One of the potential methods to be developed is molecular spectroscopy including Fourier transform infrared (FTIR) spectroscopy.

Using attenuated total reflectance (ATR) as sampling handling technique instead of transmission mode, FTIR spectroscopy offered simple, rapid, reproducible, sensitive and non-destructive, requires minimum sample preparation thus avoiding the excessive solvents. Besides, FTIR spectra also provide unique information about molecular composition due to its nature as a fingerprint technique. However, the signal obtained is rather complex which make some difficulty in spectral interpretation, thus chemometrics analysis must be used to overcome this obstacle. One of the commonly used of chemometrics techniques is multivariate calibrations which facilitate quantitative analysis of analyte(s) of interest (Bro et al., 1997; Gendrin et al., 2008). The combination of FTIR spectroscopy and multivariate calibration offers a reliable method for simultaneous determination of AO-7 and S-II. This combination has been used for quantitative analysis of coloring agents (curcuminoid) in tablet and syrups (Prabaningdyah et al., 2018; Siregar et al., 2018). However, using literature evaluation, there is no publication reporting the application of FTIR spectroscopy-multivariate calibrations for simultaneous determination of AO-7 and S-II in blusher products. Therefore, FTIR spectroscopy was developed and validated for analysis of both analytes (AO-7 and S-II) in blusher products.

\section{MATERIALS AND METHODS}

\section{Materials}

The reference standards of Acid orange 7 (AO-7) and Sudan II (S-II) were acquired from the National Agency of Drug and Food Control of the Republic of Indonesia. Solvents that used for HPLC analysis were HPLC grade from E. Merck (Darmstadt, Germany). Aquabidest was obtained from Ikapharmindo (Indonesia). Placebo was prepared by the Laboratory of Pharmaceutical Technology, STIFAR Semarang, Indonesia.

\section{Preparation of reference standards for HPLC analysis}

The stock solutions of AO7 and SII standards were prepared by weighing accurately $5.00 \mathrm{mg}$ of each standard using semi micro-analytical balance (Metler Toledo MX5) with sensitivity $0.01 \mathrm{mg}$ and then dissolved with solvent in volumetric flask $5 \mathrm{ml}$. The sonication procedure was carried out using sonicator (Elma ultrasonic, Germany) for 5 minutes after adding $3 \mathrm{ml}$ solvent. The reference standard of $\mathrm{AO} 7$ was dissolved in $3 \mathrm{ml}$ methanol, while SII was dissolved in $1 \mathrm{ml}$ acetonitrile and $2 \mathrm{ml}$ methanol. After being sonicated, methanol was added into standards until $5 \mathrm{ml}$ (each contained $1,000 \mu \mathrm{g} / \mathrm{ml}$ ). The calibration standards were constructed from standard stock solutions in the range of $10-140 \mu \mathrm{g} / \mathrm{ml}$ with acetonitrile-water $(1: 1)(\mathrm{V} / \mathrm{V})$ as solvent (Purba et al., 2019).

\section{Preparation of samples}

Sample was made by adding a certain amount of A-O7 and S-II standards to placebo. The use of placebo is based on the fact that FTIR spectroscopy combined with multivariate calibration is only suitable for certain formula. This is the limitation of the developed method. If the composition of evaluated samples is different, FTIR spectra were different so that the analyst needs to redevelop the calibration and prediction models. Therefore, FTIR spectroscopy is only applied to samples with a fixed composition. The mixture of standards and placebo was then subsequently homogenized by mortar and pestle. The concentration ranges of AO-7 and S-II spiked in 21 samples were $2 \%-20 \%$ and $0 \%-14 \%$, respectively. For HPLC analysis, a certain number of samples were accurately weighed using semi-micro analytical balance (Metler Toledo MX5) with a sensitivity of $0.01 \mathrm{mg}$ and then put into $5 \mathrm{ml}$ volumetric flask. Sample was dissolved with $2 \mathrm{ml}$ methanol and $1 \mathrm{ml}$ acetonitrile, sonicated for 5 minutes, and finally added with methanol up to $5 \mathrm{ml}$. The solution was filtered with membrane filter $0.45 \mu \mathrm{m}$ and injected into the HPLC system (Purba et al., 2019).

\section{HPLC instrumentation and condition}

Analysis of AO7 and SII was performed by RP-HPLC on Shimadzu LC 20AD equipped with M20A PDA Detector set at 300-650 nm. AO7 was detected at $482 \mathrm{~nm}$ and SII at 495 $\mathrm{nm}$, respectively. Separation was done by $\mathrm{C} 18$ column (Waters XBridge $250 \mathrm{~mm} \times 4.6 \mathrm{~mm}$ i.d., $5 \mu \mathrm{m}$ ) at temperature $40^{\circ} \mathrm{C}$ and acetonitrile-water as mobile phase that was run in gradient elution program $\mathrm{ACN} 43 \%$ at $0-1$ minute, $90 \% \mathrm{ACN}$ at $1.3-1.4$ minute, $43 \% \mathrm{ACN}$ at $14.40-19$, flow rate $0.9 \mathrm{ml} /$ minute, with injection volume of $10 \mu \mathrm{l}$.

\section{FTIR spectroscopy analysis}

Sample handling technique used was Smart iTR ${ }^{\mathrm{TM}}$ ATR. Samples were placed on the ATR sampling technique and then scanned at 4,000-650 $\mathrm{cm}^{-1}$, using 32 scans at $16 \mathrm{~cm}^{-1}$ resolution in two replications by Nicolet iS10 FTIR spectrophotometer (Thermo Fisher Scientific Inc, Madison) with deuterated triglycine sulfate 
detector and potassium bromide $(\mathrm{KBr}) / \mathrm{Germanium}$ as a beam splitter (Siregar et al., 2018). The background used was air and the FTIR spectra were acquired in absorbance values. The software of OMNIC was used to treat FTIR spectra.

\section{Multivariate analysis}

Multivariate analysis used in this study was partial least square regression (PLSR) and principal component regression (PCR) which were performed by TQ analyst 9 software that accommodated in Nicolet iS10 FTIR instrument (Thermo Fisher Scientific Inc., Madison, WI). The wavenumbers region was optimized for ensuring good model capable of predicting the levels of AO-7 and S-II accurately and precisely. Wavenumbers regions were selected if it provides the highest coefficient determination $\left(r^{2}\right)$ and the lowest values of root mean square error of calibration (RMSEC) and root mean square error of prediction (RMSEP) (Prabaningdyah et al., 2018).

\section{RESULTS AND DISCUSSION}

HPLC is a common method for analyzing dyes, especially AO-7 and S-II in cosmetic preparations due to its capability to provide the separation of analytes. Separation of analytes of interest by HPLC is more preferable because of its sensitivity, accuracy, precision, and robustness, but its complexity in sample preparation and mobile phase has attracted FTIR spectroscopy as an alternative method. FTIR spectroscopy-multivariate calibration is one of the molecular spectroscopy methods commonly used in the analysis of analytes in complex mixtures due to its simplicity, simple sample preparation, non-destructive, and not exploiting extensive reagents and solvents (Rohman et al., 2017). However, FTIR spectroscopy used for analysis in complex mixtures is secondary method; therefore, reference method (typically chromatographic techniques) was used as a reference standard to determine the actual values of analytes (AO-7 and S-II).

Figure 2 showed HPLC chromatogram during the separation of AO-7 and S-II using reversed-phase column with a PDA detector. Both analytes are well separated from each other and from matrix samples. The results of AO-7 and S-II obtained from HPLC analysis were used as actual values during quantification with FTIR spectroscopy facilitated with two multivariate calibrations of partial least square regression (PLSR) and principal component regression (PCR). Table 1 compiles the contents of AO-7 and S-II in spiked samples as determined using a validated HPLC method.

FTIR spectra of AO-7, S-II, and samples containing AO-7 and S-II were shown in Figure 3. Each band corresponds to the functional groups responsible for IR absorption present in the evaluated samples. The wide and sharp peak absorption at 3,690 $\mathrm{cm}^{-1}$ related to $\mathrm{OH}$ stretching vibration of free alcohol which not bonded to hydrogen (free-OH). Absorption at 2,918 $\mathrm{cm}^{-1}$ showed stretching vibration of saturated $\mathrm{C}-\mathrm{H}$. The peak at $1,740 \mathrm{~cm}^{-1}$ is correlated with carbonyl stretching vibration, while peak at 1,428 $\mathrm{cm}^{-1}$ is associated with $\mathrm{C}-\mathrm{H}$ bending vibration, peak at $1,004 \mathrm{~cm}^{-1}$ is absorption of secondary cyclic alcohol, while peaks at 913,878 , and $764 \mathrm{~cm}^{-1}$ were due to bending vibration of $=\mathrm{C}-\mathrm{H}$ out of plane (Pavia, 2009). There are different peaks existed at wavenumbers of 3,450-2,400 $\mathrm{cm}^{-1}$; therefore, some wavenumbers regions were optimized to get the acceptable prediction models.

Two multivariate calibrations of PLSR and PCR were investigated during developing models using FTIR spectra at different wavenumbers and different spectral treatment (normal and derivatives). PLSR and PCR could resolve the overlapping

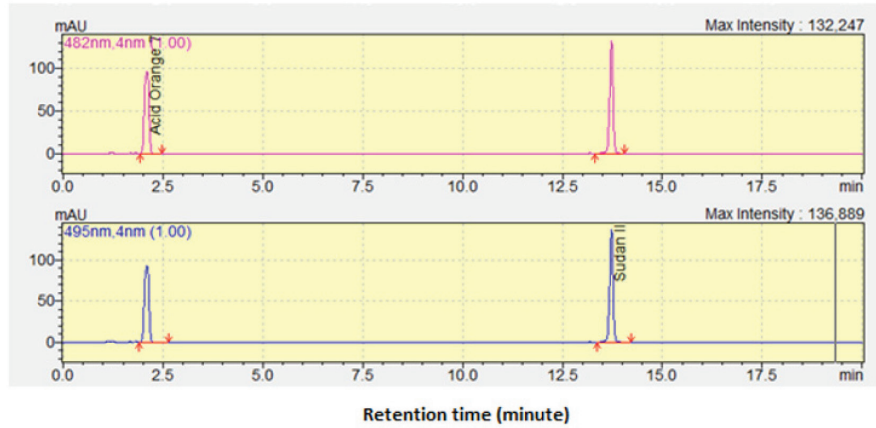

Figure 2. RP-HPLC chromatogram for separation of Acid Orange 7 and Sudan II. For condition, see the section of HPLC instrumentation and Condition in Materials and Methods.

Table 1. The performance of multivariate calibrations of PLSR and PCR for the prediction of AO-7 and SII using FTIR spectroscopy. $r=$ coefficient of correlation; RMSEC = root mean square error of calibration; RMSEP $=$ root mean square error of prediction.

\begin{tabular}{|c|c|c|c|c|c|c|c|c|c|c|c|}
\hline \multirow{3}{*}{$\begin{array}{l}\text { Multivariate } \\
\text { Calibration }\end{array}$} & \multirow{3}{*}{ Wavenumber $\left(\mathrm{cm}^{-1}\right)$} & \multirow{3}{*}{ Region type } & \multirow{3}{*}{$\begin{array}{c}\text { Number } \\
\text { of factors }\end{array}$} & \multicolumn{4}{|c|}{ AO7 } & \multicolumn{4}{|c|}{ SII } \\
\hline & & & & \multicolumn{2}{|c|}{ Calibration } & \multicolumn{2}{|c|}{ Validation } & \multicolumn{2}{|c|}{ Calibration } & \multicolumn{2}{|c|}{ Validation } \\
\hline & & & & RMSEC & $r$ & RMSEP & $r$ & RMSEC & $r$ & RMSEC & $r$ \\
\hline \multirow{6}{*}{ PLSR } & $3,999.65-650$ & $1^{\text {st }} \mathrm{der}$ & 3 & 0.513 & 0.9947 & 0.536 & 0.9945 & 0.399 & 0.9947 & 0.421 & 0.9943 \\
\hline & $4,000-1,200$ & $1^{\text {st }}$ der & 2 & 0.815 & 0.9866 & 0.756 & 0.9885 & 0.289 & 0.9972 & 0.270 & 0.9977 \\
\hline & $3,450-2,400$ & $1^{\text {st }}$ der & 8 & 0.0537 & 0.9999 & 0.621 & 0.9923 & 0.0326 & 1.0000 & 0.419 & 0.9944 \\
\hline & $1,620-1,058$ & $1^{\text {st }}$ der & 4 & 0.447 & 0.9960 & 0.638 & 0.9918 & 0.0401 & 0.9999 & 0.171 & 0.9990 \\
\hline & $1,500-770$ & $1^{\text {st }}$ der & 5 & 0.308 & 0.9981 & 0.648 & 0.9921 & 0.135 & 0.9994 & 0.195 & 0.9988 \\
\hline & $1,200-650$ & $1^{\text {st }}$ der & 3 & 0.454 & 0.9959 & 0.494 & 0.9953 & 0.328 & 0.9964 & 0.358 & 0.9959 \\
\hline \multirow{6}{*}{ PCR } & $3,999,65-650$ & $1^{\text {st }} \mathrm{der}$ & 10 & 0.277 & 0.9985 & 0.535 & 0.9945 & 0.166 & 0.9991 & 0.174 & 0.9990 \\
\hline & $4,000-1,200$ & $1^{\text {st }} \mathrm{der}$ & 10 & 0.341 & 0.9977 & 0.545 & 0.994 & 0237 & 0.9981 & 0.227 & 0.9983 \\
\hline & $3,450-2,400$ & $1^{\text {st }} \mathrm{der}$ & 10 & 0.254 & 0.9987 & 0.615 & 0.9920 & 0.204 & 0.9986 & 0.449 & 0.9935 \\
\hline & $1,620-1,058$ & $1^{\text {st }}$ der & 10 & 0.276 & 0.9985 & 0.484 & 0.9955 & 0.134 & 0.9994 & 0.145 & 0.9993 \\
\hline & $1,500-770$ & $1^{\text {st }}$ der & 10 & 0.264 & 0.9986 & 0.612 & 0.9929 & 0.116 & 0.9995 & 0.157 & 0.9992 \\
\hline & $1,200-650$ & $1^{\text {st }}$ der & 10 & 0.264 & 0.9986 & 0.548 & 0.9944 & 0.187 & 0.9988 & 0.205 & 0.9986 \\
\hline
\end{tabular}



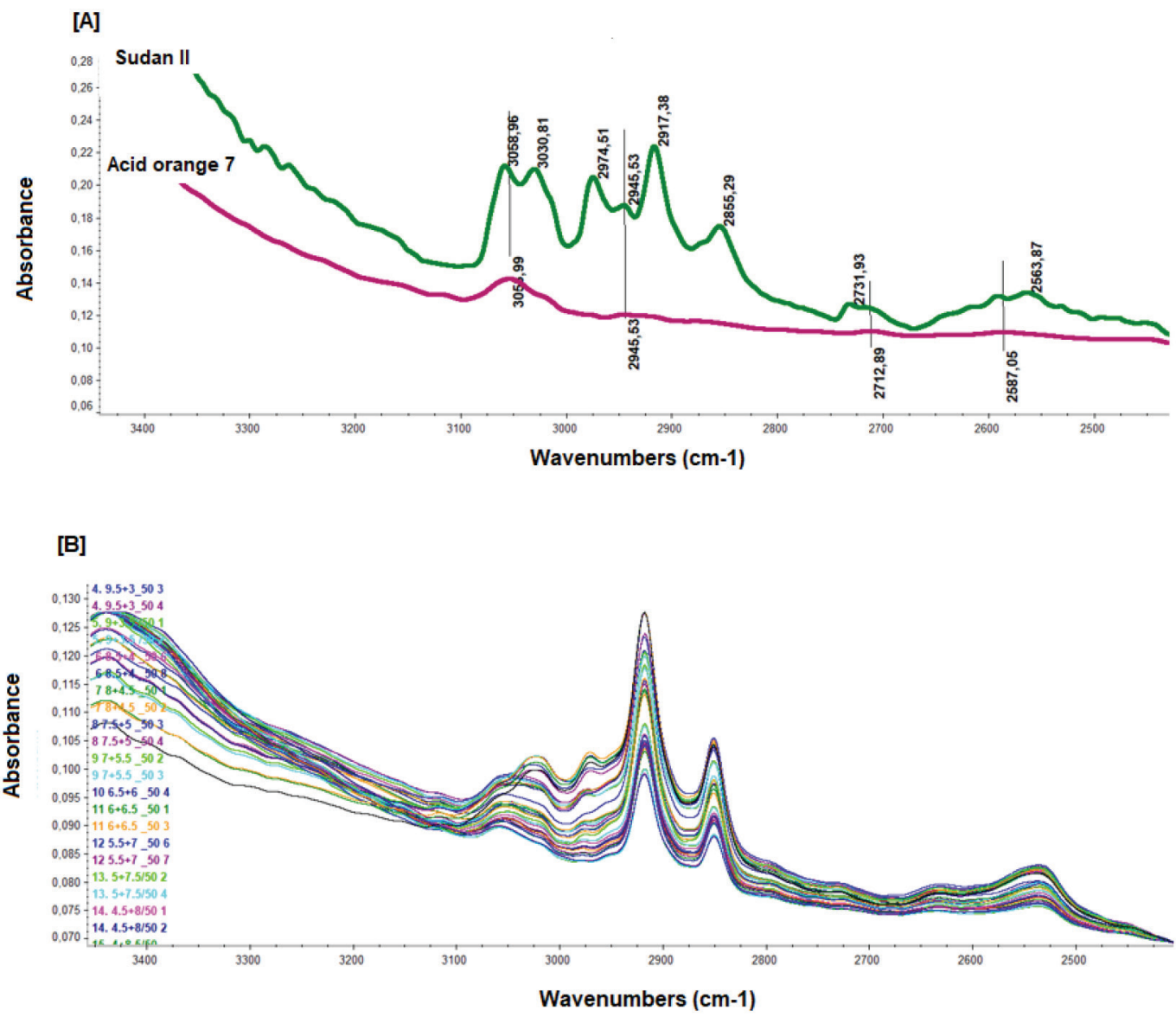

Figure 3. FTIR spectra of reference standards of Acid Orange (AO-7) and Sudan II (S-II) (A) and those in sample of blusher products (B) scanned at wavelength $3,450-2,400 \mathrm{~cm}^{-1}$ which used for prediction.

spectra from several analytes in the sample. PLSR and PCR involve a suitable calibration set so that it has the adequate capability for resulting good prediction (Bro et al., 2005; Khajehsharifi et al., 2012). The condition selected was based on the combinations (multivariate calibrations, wavenumbers region, spectral treatments) offering the best coefficient of correlation ( $r$-value) with low RMSEC and RMSEP values. Table 1 compiles the statistical parameters during the optimization process. Finally, PLSR at wavenumbers of $3,450-2,400 \mathrm{~cm}^{-1}$ using the first derivative spectra provide the best calibration models in terms of highest $r$-values and low values of RMSEC and RMSEP. The $r$-values acquired during the analysis of AO-7 were 0.9998 in calibration and 0.9847 in prediction samples, respectively. In addition, the values of RMSEC and RMSEP values were $0.054 \%$ and $0.621 \%$, respectively. Calibration model of actual and predicted values correlation is shown in Figure 4.

The developed calibration models of AO-7 and S-II were internally validated using cross validation with leave one out technique by removing samples one by one, and the removed samples were predicted with new calibration equation calibration of correlation after one sample is being removed (Miller and Miller, 2005). The actual and the predicted samples during cross validation were correlated, as shown in Figure 5. Two statistical parameters, namely, the coefficient of correlation $(r)$ and root mean square error of cross validation (RMSECV) were used for evaluating the validation performance. The $r$-value and RMSEC value obtained
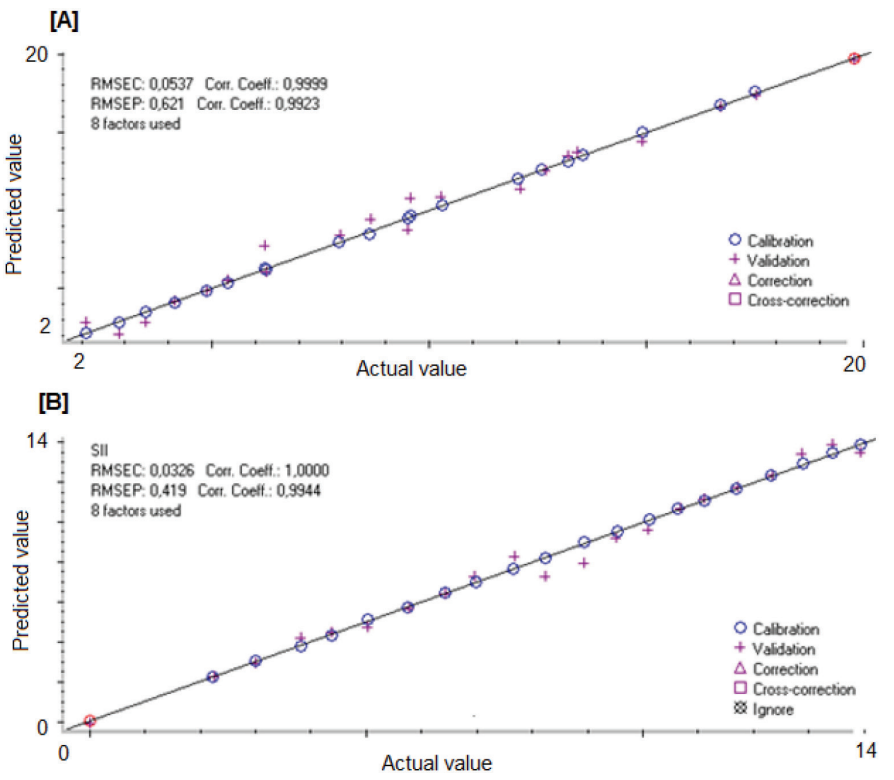

Figure 4. PLS Regression for the correlation between actual values ( $\mathrm{x}$-axis) and FTIR predicted values of Acid Orange 7 (A) and Sudan II (B) in calibration models.

were $0.9943 \%$ and $0.542 \%$ (for AO- 7 ) and $0.9946 \%$ and $0.416 \%$ (for $\mathrm{S}-\mathrm{II}$ ), respectively. Based on the high $r$-value and low error values, it can be concluded that the optimized FTIR spectroscopy was valid 


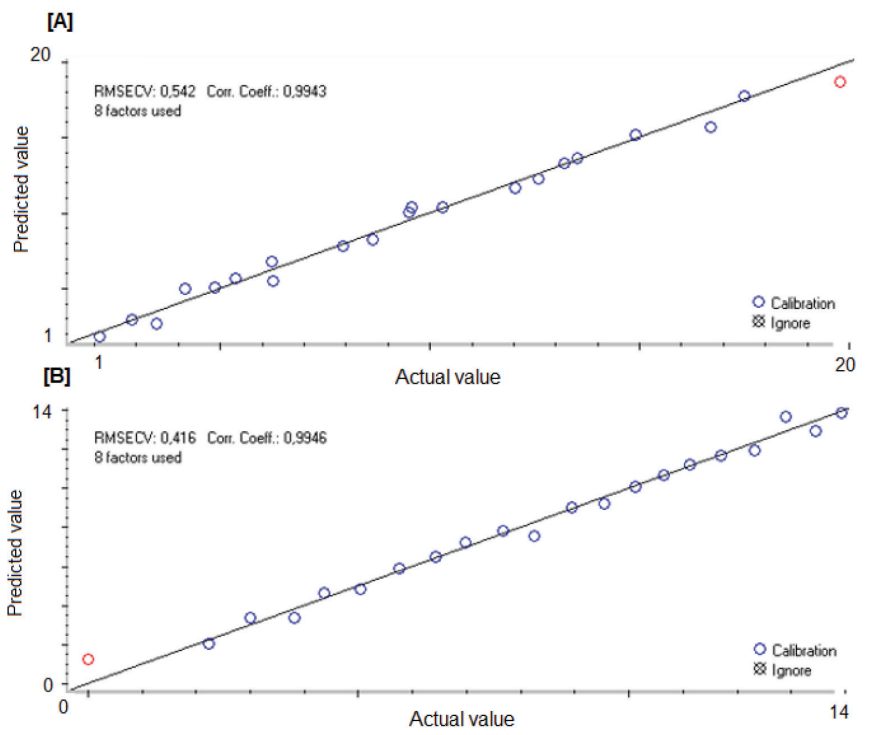

Figure 5. PLS regression for the correlation between actual values (x-axis) and FTIR predicted values of Acid Orange 7 (A) and Sudan II (B) in internal calibration models using "leave one out" technique.

Table 2. The correlation between actual values of Acid Orange (AO-7) as well as Sudan II (S-II) determined using HPLC and predicted values using FTIR spectroscopy-partial least square.

\begin{tabular}{|c|c|c|c|c|}
\hline \multirow[b]{2}{*}{ Samples } & \multicolumn{2}{|c|}{ AO-7 } & \multicolumn{2}{|r|}{ S-II } \\
\hline & $\begin{array}{c}\text { Actual } \\
\text { values } \\
\text { HPLC (\%) }\end{array}$ & $\begin{array}{l}\text { Predicted values } \\
\text { using FTIR } \\
\text { spectroscopy (\%) }\end{array}$ & $\begin{array}{c}\text { Actual } \\
\text { values } \\
\text { HPLC (\%) }\end{array}$ & $\begin{array}{c}\text { Predicted values } \\
\text { using FTIR } \\
\text { spectroscopy (\%) }\end{array}$ \\
\hline 1 & 19.78 & 19.79 & 0 & 0.14 \\
\hline 2 & 17.5 & 17.39 & 2.23 & 2.23 \\
\hline 3 & 16.72 & 16.88 & 3.01 & 3.07 \\
\hline 4 & 14.9 & 14.79 & 3.81 & 3.75 \\
\hline 5 & 13.53 & 13.68 & 4.37 & 4.36 \\
\hline 6 & 13.21 & 13.25 & 5.03 & 4.75 \\
\hline 7 & 12.59 & 12.54 & 5.76 & 5.7 \\
\hline 8 & 12.04 & 11.98 & 6.42 & 6.55 \\
\hline 9 & 10.28 & 10.27 & 6.96 & 7.06 \\
\hline 10 & 9.5 & 9.48 & 7.67 & 7.7 \\
\hline 11 & 9.56 & 9.6 & 8.24 & 8.22 \\
\hline 12 & 8.63 & 8.56 & 8.93 & 8.89 \\
\hline 13 & 7.9 & 7.89 & 9.52 & 9.65 \\
\hline 14 & 6.21 & 6.29 & 10.1 & 9.89 \\
\hline 15 & 6.25 & 6.23 & 10.64 & 10.83 \\
\hline 16 & 5.36 & 5.27 & 11.12 & 10.97 \\
\hline 17 & 4.87 & 4.91 & 11.7 & 11.61 \\
\hline 18 & 4.16 & 4.12 & 12.33 & 12.36 \\
\hline 19 & 3.47 & 3.42 & 12.9 & 13 \\
\hline 20 & 2.88 & 2.95 & 13.44 & 13.72 \\
\hline 21 & 2.12 & 2.18 & 13.94 & 13.68 \\
\hline Equation & \multicolumn{2}{|c|}{$y=0.9998 x+0.0023$} & \multicolumn{2}{|c|}{$y=0.9985 x+0.0124$} \\
\hline$r$ & \multicolumn{2}{|c|}{0.9999} & \multicolumn{2}{|c|}{0.9993} \\
\hline RMSEC & \multicolumn{2}{|c|}{$0.0742 \%$} & \multicolumn{2}{|c|}{$0.141 \%$} \\
\hline
\end{tabular}

to predict the levels of AO-7 and S-II in the blusher products. The developed method was finally used for the prediction of unknown samples. The correlation between actual values of AO-7 as well as S-II determined using HPLC and predicted values using FTIR spectroscopy-PLSR was compiled in Table 2.

Based on these results, FTIR spectroscopy combined with PLSR was an effective method for prediction of AO-7 and S-II and could be used as an alternative method for HPLC analysis. The main problem of this method is that the calibration model can be used only for samples similar to those tested in this study. If the composition of the samples to be analyzed is different, FTIR spectra of the analytes will also be different. Consequently, the calibration model needs to be redeveloped using different regions. It is important to do studies on the effect of different placebo to the content AO-7 and S-II using this model.

\section{CONCLUSION}

FTIR spectroscopy combined with the multivariate calibration of PLS regression using first derivative spectra at wavenumbers of $3,400-2,400 \mathrm{~cm}^{-1}$ were accurate and precise enough for determining AO-7 and S-II in blusher product with acceptable statistical results in term of high $\mathrm{R}$ value and low RMSEC, RMSECV, and RMSEP. Although laboratories have HPLC commonly, simplicity of data processing compare to PLS, the developed method could be used as an alternative method toward HPLC method for routine analysis of both components. This method is fast, low cost, and environmentally friendly; therefore, this method could be regarded as green analytical chemistry technique.

\section{ACKNOWLEDGMENTS}

The authors would like to thank Universitas Gadjah Mada for supporting the publication of this article through the scheme of Penelitian Terapan Unggulan Perguruan Tinggi (PTUPT 2019) awarded to Prof. Dr. Abdul Rohman with contract number 2717/UN1.DITLIT/DIT-LIT/LT/2019.

ABBREVIATION LIST
$\begin{array}{ll}\text { AO-7 } & \text { Acid orange 7 } \\ \text { ATR } & \text { Attenuated total reflectance } \\ \text { FTIR } & \text { Fourier transform infrared } \\ \text { HPLC } & \text { High-performance liquid chromatography } \\ \text { PCR } & \text { Principal component regression } \\ \text { PDA } & \text { Photodiode array } \\ \text { PLSR } & \text { Partial least square regression } \\ \text { S-II } & \text { Sudan II } \\ \text { RMSEC } & \text { Root mean square error of calibration } \\ \text { RMSECV } & \text { Root mean square error of cross validation } \\ \text { RMSEP } & \text { Root mean square error of prediction }\end{array}$

\section{CONFLICT OF INTEREST}

The authors have declared "no conflicts of interest with respect to the research, authorship, and/or publication of this article".

\section{AUTHORS' CONTRIBUTION}

NBRP performed research activity, compiled data, and prepared manuscript. AR and SM designed research activities, prepared manuscript, and made critical thinking on the manuscript. 


\section{REFERENCES}

An Y, Jiang L, Cao J, Geng C, Zhong L. Sudan I induces genotoxic effects and oxidative DNA damage in HepG2 cells. Mutat Res, 2007; 627:164-70.

Ben Mansour H, Corroler D, Barillier D, Ghedira K, Chekir L, Mosrati R. Evaluation of genotoxicity and pro-oxidant effect of the azo dyes: acids yellow 17, violet 7 and orange 52, and of their degradation products by Pseudomonas putida mt-2. Food Chem Toxicol, 2007; 45:1670-7.

Bro R, Jerome JW, Paul RM, Kowalski BR. Review of chemometrics applied to spectroscopy: 1985-95, part 3-multi-way analysis. App Spectros Rev, 1997; 32:237-61.

Bro R, Rinnan Å, Faber N, Klaas M. Standard error of prediction for multilinear PLS. Chem Intel Lab Systems, 2005; 75:69-76.

Buzek J, Ask B. Regulation (EC) No 1223/2009 of the European Parliament and of the Council of 30 November 2009 on cosmetic products. Off J Eur Union L342, 2009; 52:59-209.

Ertas E, Ozer H, Alasalvar C. A Rapid HPLC method for determination of Sudan dyes and para red in red chilli pepper. Food Chem, 2007; 105:756-60.

Fardouly J, Vartanian LR. Social media and body image concerns: current research and future directions. Curr Opin Psychol, 2016; $9: 1-5$.

Gendrin C, Roggo Y, Collet, C. Pharmaceutical applications of vibrational chemical imaging and chemometrics: a review. J Pharm Biomed Anal, 2008; 48:533-53.

Guerra E, Llompart M, Garcia-Jares C. Analysis of dyes in cosmetics: challenges and recent developments. Cosmetics, 2018; 5:47; doi:10.3390/cosmetics5030047

Ju C, Tang Y, Fan H, Chen J. Enzyme-linked immunosorbent assay (ELISA) using a specific monoclonal antibody as a new tool to detect Sudan dyes and para red. Anal Chim Acta, 2008; 621:200-6.

Khajehsharifi H, Pourbasheer E, Tavallali H, Sarvi S. Sadeghi M. The comparison of partial least squares and principal component regression in simultaneous spectrophotometric determination of ascorbic acid, dopamine and uric acid in real samples. Arabian J Chem, 2017; 10:S3451-8.

Kucharska M, Grabka J. A review of chromatographic methods for determination of synthetic food dyes. Talanta, 2010; 80:1045-51.

Miller JN, Miller JC. 2005. Statistics and chemometrics for analytical chemistry. 5th edition, Pearson Education Limited, Edinburgh, UK.
Pan H. Effects of Orange II and Sudan III azo dyes and their metabolites on Staphylococcus aureus. J Indust Microbiol Biotechnol, 2011; 38:1729-38.

Pavia DL. Introduction to spectroscopy. Belmont: Cengage Learning, 2009.

Prabaningdyah NK, Riyanto S, Rohman A. Application of FTIR spectroscopy and multivariate calibration for analysis of curcuminoid in syrup formulation. J Appl Pharm Sci, 2018; 8:172-9.

Purba NBR, Rohman A, Martono S. The optimization of HPLC for quantitative analysis of acid orange 7 and Sudan II in cosmetic products using box behnken design. IntJ Appl Pharm, 2019;11:130-7.

Rebane R, Leito, I. Yurchenko S, Herodes K. A review of analytical techniques for determination of Sudan I-IV dyes in food matrixes. J Chromatogr A, 2010; 1217:2747-57.

Rohman A, Man YBC. The chemometrics approach applied to FTIR spectral data for the analysis of rice bran oil in extra virgin olive oil Chem Intel Lab Systems, 2012; 110:129-34.

Siregar C, Martono S, Rohman A. Application of Fourier transform infrared (FTIR) spectroscopy coupled with multivariate calibration for quantitative analysis of curcuminoid in tablet dosage form. J Appl Pharm Sci, 2018; 151-6.

Souto N, Catia SC. Analysis of early synthetic dyes with HPLCDAD-MS an important database for analysis of colorants used in cultural heritage. Universidade de Lisboa, Faculdade de Ciências e Tecnologias, Lisbon, Portugal, pp 8-11, 2010.

Yamjala K, Nainar MS, Ramisetti, NR. Methods for the analysis of azo dyes employed in food industry - a review. Food Chem, 2016; 192:813-24.

How to cite this article:

Purba NBR, Rohman A, Martono S. Application of FTIR spectroscopy and multivariate calibration for determination of Acid Orange 7 and Sudan II in blusher products. J Appl Pharm Sci, 2019; 9(11):112-117. 